\title{
Preferences and Perceived Barriers to Treatment for Depression during the Perinatal Period
}

\author{
Heather A. O'Mahen, Ph.D. ${ }^{1}$ and Heather A. Flynn, Ph.D. ${ }^{2}$
}

\begin{abstract}
Background and methods: Little is understood about why few women during the perinatal period will use depression treatment. In particular, beliefs and barriers related to depression treatment use have not been studied. In this study, African American and white pregnant women $(n=108)$ who screened $\geq 10$ on the Edinburgh Postnatal Depression Scale (EPDS) were asked about recent formal and informal treatment use in prenatal care settings. Confidence in the helpfulness of treatment, providers, and settings and perceived barriers to treatment were assessed and compared between African American and white women.

Results: Pregnant women overall reported low rates of formal treatment use but frequently sought help from informal sources, such as friends, family, and printed materials. All women expressed greatest confidence in psychosocial treatments and lowest confidence in antidepressants. African American women reported less confidence in advice from family and friends and in antidepressants than did white women. Women expressed greatest confidence in treatments delivered by mental health professionals and religious leaders. African American women sought help more frequently and had significantly more confidence in religious leaders as treatment deliverers than white women. Women had greatest confidence in treatments delivered in professional and home settings, with African American women expressing greater confidence in religious settings than white women. All women reported greatest concern with structural barriers, compared with attitudinal and knowledge barriers.

Conclusions: Understanding patterns of treatment use, beliefs, and barriers to depression treatment provides important information for tailoring and improving appropriate use of mental health treatment in women during the perinatal period.
\end{abstract}

\section{Introduction}

A GREAT DEAL OF RECENT national attention has focused on both treatment issues for perinatal depression ${ }^{1}$ and racial disparities in mental health treatment. ${ }^{2-4}$ Despite the fact that close to 1 in 4 women may experience depression during the perinatal period, most are unlikely to receive effective treatments. ${ }^{5}$ African American women are less likely to seek depression treatment than are white women. ${ }^{6,7}$ Evidence of pregnancy and birth complications associated with untreated depression points to the need for research addressing factors underlying low treatment rates among depressed women around the time of childbirth, as well as racial differences in these factors. Results from the National Institutes of Mental Health Sequenced Treatment Alternatives to Relieve Depression (NIMH STAR-D) study further highlight the importance of effective treatment of maternal depression by demonstrating changes in children's mental health diagnoses and symptoms associated with maternal depression remission. ${ }^{8}$ Other recent studies and Food and Drug Administration (FDA) advisories regarding possible fetal risk associated with antidepressant medications during pregnancy may lead to confusion about safe and effective treatments for perinatal depression. ${ }^{9-11}$ Given women's vulnerability to depression and the dual impact it has on both women and their children during the perinatal period, it is especially important to understand factors guiding women's treatment choices during this time in order to improve rates of effective treatment. The present study aimed to add to the literature by examining women's beliefs about treatment and their perceived barriers to receiving treatment and to examine racial and socioeconomic differences in these treatment-related issues.

\footnotetext{
${ }^{1}$ University of Exeter, Exeter, U.K.

${ }^{2}$ University of Michigan, Ann Arbor, Michigan.

This work was supported by a Psychiatry Research Council Grant (H.A.F./H.A.O.) and a Rachel Upjohn Scholars Award (H.A.O.) from the Department of Psychiatry, University of Michigan.
} 
To date, little is known about factors involved in depressed women's decisions to use treatment, particularly during pregnancy and the postpartum period. Research in this area has focused primarily on structural factors (such as low socioeconomic level and lack of transportation) on poor treatment use. ${ }^{12,13}$ A recent study by Flynn et al., ${ }^{5}$ however, found low rates of treatment use among a sample comprising primarily insured, relatively highly educated pregnant women with depression. In that study, low treatment rates for depression were found despite the fact that all women had access during their obstetrics visit to a mental health clinician offered at no fee. That study and others points to the need to broaden our understanding of factors involved in women's use of mental health treatment. Emerging research has demonstrated that decisions to use treatment are impacted by both prompts and barriers to mental health treatment use. ${ }^{14}$ Individual beliefs may be a critical prompt for treatment. $3,4,15$ Positive treatment beliefs have been linked with increased mental health treatment use. ${ }^{16,17}$ Conversely, individuals who endorse beliefs that treatment would be of little help are less willing to seek mental health treatment. ${ }^{18}$ Confidence about individual change has also been shown to predict depression treatment adherence in general patient populations. ${ }^{19}$

Little is known, however, about women's beliefs about the helpfulness of mental health treatment around the time of pregnancy. Two studies to date have investigated women's treatment preferences in low-income, public health clinic obstetrics/gynecology settings. Alvidrez and Azocar ${ }^{20}$ found that women were broadly interested in receiving mental health treatment, expressing greatest interest in psychotherapy and psychoeducation about health and stress and least interest in medication or group therapy. In a similar sample, highlighting the importance of understanding both formal and informal mechanisms of treatment use, Scholle and Kelleher ${ }^{21}$ reported that $33 \%$ of women preferred information about mental health issues from informal sources (e.g., printed material, friends), and 5\% did not want any advice about mental health. In that study, those who did want mental health advice (63\%) from formal sources (any health professional) indicated that they most preferred to receive that advice from an obstetrician/gynecologist (23\%), mental health professional $(25 \%)$, or general medical doctor $(14 \%)$.

These results suggest that beliefs about the helpfulness of treatment may have a strong role in understanding mental health treatment use. Such investigations are particularly salient for racial or ethnic minorities, where there are often widely disparate rates of mental health use and a greater risk for persistent symptoms. ${ }^{2,22}$ For example, in one qualitative study, African American women expressed strong preferences for receiving help from religious sources and reported believing that traditional mental health services were not intended for them. ${ }^{23}$ African Americans have also reported finding medication treatment less acceptable, expressing a preference for counseling. ${ }^{24,25}$ Understanding how beliefs vary across racial groups is, therefore, potentially critical to improving women's access to and use of depression treatment.

Even when positive beliefs about treatment are expressed, barriers to treatment may interefere with actual treatment use. ${ }^{14,26}$ In addition to structural barriers, recent research has highlighted the role of negative attitudes and lack of knowledge about depression in poor treatment use. ${ }^{14,26,27}$ Reviews of the literature suggest that concerns about how others per- ceive depression (e.g., to be a personal weakness) ${ }^{23}$ are particularly salient factors in depression treatment use among racial minorities. $7,28,29$

Although this growing body of research highlights the role of beliefs about the helpfulness of treatment and perceived barriers in predicting actual treatment use, few studies have examined these factors during the perinatal period. The perinatal period merits specific focus, as depressed women may experience unique physical and psychological demands as a consequence of pregnancy and childbirth. These demands may, in turn, alter women's confidence and perceived barriers regarding mental health treatment. For example, women may likely find antidepressant treatment less acceptable, given that pregnant and breastfeeding women often are concerned about the impact of medication on the fetus. ${ }^{20,30}$ Women suffering from perinatal depression may also have unique concerns about barriers to treatment. For instance, women have reported reluctance to admit to their low mood because of feelings of guilt and stigma about being depressed during a time society regards as a happy period. ${ }^{31}$ In one study, depressed pregnant women who refused psychotherapy reported they did so because they were "not depressed enough" or "did not want to be labeled."32 Women suffering from perinatal depression may also experience more trouble with transportation or difficulty accessing treatment because of child care concerns.

The present study examined psychological factors impacting pregnant women's use of mental health treatment among a group of pregnant women who scored $\geq 10$ on the Edinburgh Postnatal Depression Scale (EPDS). Women's formal and informal mental health treatment use in the 6 months prior to their participation in the study was examined. In addition, both confidence in the helpfulness of treatment and perceived barriers to treatment were investigated. This study extended previous research on mental health treatment use during pregnancy by examining both formal (mental health professional) and informal (discussed with family) mental health treatment. Further, this study builds on previous research on beliefs about and preferences for depression treatment ${ }^{19}$ by investigating pregnant women's beliefs about their confidence in the helpfulness of treatment for depression treatment along three dimensions: treatment type (e.g., seeking social support, antidepressant medication), treatment provider (e.g., obstetrician, mental health professional), and treatment delivery mode (e.g., professional office, internet). Consistent with research suggesting that attitudinal, structural, and knowledge factors are particularly relevant barriers to treatment, ${ }^{14}$ we examined women's relative endorsement of these three barriers. An important aim of this study was to examine differences in beliefs and barriers to treatment between African American and white women in the study sample.

\section{Materials and Methods}

\section{Participants and procedures}

Eligible women were recruited in the waiting rooms of four Midwestern area obstetrical/gynecological clinics in the United States between 2004 and 2007. One of the clinics was associated with a university hospital in a suburban setting. The other three clinics were part of a nonprofit organization focused on treating underserved populations in urban settings. The samples from the suburban and urban clinics were 
TABle 1. Demographics

\begin{tabular}{|c|c|c|c|}
\hline \multirow[b]{2}{*}{ Variable } & Overall & Suburban & Urban \\
\hline & \multicolumn{3}{|c|}{$\%(\mathrm{n})$ [or Mean $(S D)]^{*}$} \\
\hline \multicolumn{4}{|l|}{ Age, $^{\text {a }}$ years } \\
\hline $18-27$ & $59.6(65)$ & $36.5(40)$ & $75.0(81)$ \\
\hline $28-42$ & $40.4(43)$ & $43.5(48)$ & $25.0(27)$ \\
\hline \multicolumn{4}{|l|}{ Race } \\
\hline African American & $51.0(55)$ & $6.3(6)$ & $68.3(73)$ \\
\hline White & $40.8(53)$ & $78.0(84)$ & $28.6(31)$ \\
\hline \multicolumn{4}{|l|}{ Income $^{a}$} \\
\hline $0-\$ 19,999$ & $45.0(49)$ & $8.4(9)$ & $74.1(80)$ \\
\hline \multicolumn{4}{|l|}{ Health insurance } \\
\hline Private insurance & $24.5(26)$ & $50.0(54)$ & $8.8(10)$ \\
\hline Medicaid & $65.3(70)$ & $20.5(23)$ & $80.0(86)$ \\
\hline No insurance & $4.1(4.3)$ & $2.0(2)$ & $3.1(3)$ \\
\hline \multicolumn{4}{|l|}{ Marital status ${ }^{\mathrm{a}}$} \\
\hline Married & $44.9(49)$ & $83.0(90)$ & $15.1(16)$ \\
\hline Live-in partner & $22.4(24)$ & $13.3(14)$ & $42.8(46)$ \\
\hline Not in a relationship & $28.6(31)$ & $1.3(1)$ & $40.3(43)$ \\
\hline How many children (not including pregnancy) & $1.82(1.78)$ & $1(1.04)^{*}$ & $1.32(1.30)$ \\
\hline \multicolumn{4}{|l|}{ Weeks pregnant } \\
\hline $0-12$ & $15.1(16)$ & $39.4(42)$ & $19.7(22)$ \\
\hline $13-24$ & $42.3(45)$ & $24.5(27)$ & $37.6(41)$ \\
\hline $25-40+$ & $42.4(45)$ & $35.1(38)$ & $42.7(46)$ \\
\hline \multicolumn{4}{|l|}{ Education $^{\mathrm{a}}$} \\
\hline Less than high school & $21.3(23)$ & $7.0(8)$ & $35.6(39)$ \\
\hline High school/GED & $28.6(31)$ & $12.7(15)$ & $32.5(36)$ \\
\hline More than high school & $46.8(51)$ & $80.1(86)$ & $31.9(35)$ \\
\hline \multicolumn{4}{|l|}{ Current work status } \\
\hline Homemaker & $50.0(54)$ & $34.4(38)$ & $37.3(40)$ \\
\hline Employed & $21.7(24)$ & $58.0(63)$ & $27.5(30)$ \\
\hline
\end{tabular}

aSignificant racial differences.

ethnically and socioeconomically representative of the populations from which they were drawn (Table 1, U.S. Bureau of the Census, 2005).

All women were approached by research assistants in the waiting area, told about the study, and provided informed written consent. To be eligible for the study, women had to be $\geq 18$ years, currently pregnant, and seeking prenatal care. Of the 532 women approached, 84\% $(n=447)$ were eligible for the study based on these criteria and consented to complete the screening survey. Reasons for nonparticipation included not eligible, $6 \%(n=32)$ and not interested/not enough time, $10 \%(n=53)$. The screening survey included the following measures: the EPDS, 33 one question assessing past depression (Has there ever been a period, at any point in your life, where you felt depressed, irritable, or lost interest in pleasurable activities and had some of the symptoms listed above nearly every day for a period of at least 2 weeks?), and four questions assessing current social stress on a 5-point Likert scale ranging from "not at all" to "extremely" (How "stressed" have you felt in the past 2 months? How much conflict have you had with those whom you care about in the past 2 months? When you experience problems/stress, to what extent to do you feel you can seek out support from those whom you care about? When you experience problems/stress, to what extent do you seek out support from those whom you care about?). These items were adapted from current research on stress and social support, which has demonstrated a strong link between perceived stress and interpersonal conflict and the onset of depression. ${ }^{34,35}$

Measures of demographics, including age, socioeconomic level, and race, were also included in the screen. Women who (1) scored $\geq 10$ on the EPDS or (2) indicated that they suffered from past depression and were experiencing significant current stress (operationally defined as a summed score of $\geq 4$ on the social stress scale) were determined to be eligible for a baseline interview. These inclusion criteria for the baseline interview were selected based on previous research showing that pregnant women with scores of $\geq 10$ on the EPDS or a history of depression and current social stress (or both) are at risk for developing clinical depression. ${ }^{36-38}$

Of the women who consented to participate in the study ( $n=447), 39 \%(n=174)$ were determined to be at risk for depression. (Depression risk is subsequently defined as "EPDS score 10 or greater, or having experienced past depression and currently undergoing significant social stress, defined as a score of 4 or greater on the social stress questions.") The loss to the study of women in our risk group who miscarried during the course of the study $(2 \%, n=3)$, were not able to be contacted despite multiple attempts $(32 \%$, $n=56)$, or declined further participation $(4 \%, n=7)$ resulted in a total depression risk sample of 108 . This rate of attrition is typical for studies involving similar innercity samples. ${ }^{39,40}$ Eligible women were contacted via telephone within 3 weeks of their screening visit and asked to complete an interview. The interview included measures of depression severity, use 
of mental health services, preferences for mental health treatment, and barriers to treatment. Interviews lasted approximately 1 hour and were conducted via telephone $(55 \%, n=$ $59)$ or in the woman's home $(45 \%, n=49)$, based on the woman's preference.

\section{Measures}

Edinburgh Postnatal Depression Scale. The 10-item EPDS was used as the depression screening tool in this study. ${ }^{33}$ Originally developed to assess postpartum symptoms, the EPDS has also been validated in prenatal samples. ${ }^{36}$ Using a cutoff score of 10 , the EPDS has a sensitivity of $90 \%$ and specificity of $78 \%-88 \%$ for the identification of both minor and major depression. ${ }^{1,36}$ Previous research with similar samples of pregnant women has found that when using a cutoff of $10,74 \%$ of women met diagnostic criteria for depression using the Mood Disorders Module of the Structured Clinical Interview for DSM-IV (SCID). ${ }^{5}$

Depression treatment use. Depression treatment use was measured with items assessing formal specialty depression treatment services (e.g., How many times have you met or spoken with a mental health professional about your mood in the last 6 months?), including information about locations (e.g., inpatient, outpatient, community mental health center) and providers (e.g., psychiatrists, social workers, psychologist, nurses). Analyses of data from this questionnaire focused on whether or not participants sought treatment for depression (medication or counseling/psychotherapy) at any point during the study period. Treatment use was coded as a binary variable (yes/no) based on whether participants reported using antidepressant medication or counseling/ psychotherapy during the 6 months leading up to and including the date of the baseline interview. Women were also asked about the frequency with which they sought out formal and informal treatment sources during the previous 6 months (e.g., How frequently have you spoken to someone in your family about your mood [depression]?). Responses were coded on a 5-point Likert scale (range 1, never, to 5, very often).

Confidence in helpfulness of mental health treatment. Women were asked to indicate their confidence in the helpfulness of mental health treatment across setting, provider, and treatment type. Participants were asked to choose which provider, setting, and treatment type they preferred from a list of choices (e.g., mental health specialist, primary care physician, obstetrician). They were then asked to indicate on a 5-point Likert scale how confident they were that each person, setting, and treatment type could help them with their depression (range 1, not at all confident, to 5, very confident).

Barriers to treatment. Barriers to seeking treatment were assessed, using a study-specific measure, along three dimensions supported by the literature linking perceived barriers to mental health treatment: attitudinal, knowledge, and structural. ${ }^{14,26}$ Items comprising the structural barriers scale were adapted from the work of Scholle et al. ${ }^{12}$ examining women's perceived structural barriers to treatment. Attitudinal and knowledge items associated with depression treatment use were adapted from studies examining use of treatment in depressed samples (see Appendix for list of items).
Items were assessed using a 5-point Likert scale ("not at all" to "completely") querying women about the extent to which each item prevented them from seeking treatment for depression.

\section{Data plan}

Descriptive analyses (means and frequencies) of rates of treatment use, women's treatment preferences, and perceived barriers to treatment were performed first. Differences in demographic data by race, socioeconomic level, and depression were calculated using Chi-square. Consistent with previous research investigating depressed individual's use of mental health treatment, 5,19 the data on women's formal and informal treatment use within the past 6 months and their confidence for the helpfulness of treatment were positively skewed. Square root transformations normalized the data for mean scores on measures of women's treatment history and confidence in the helpfulness of treatment. Differences in African American and Caucasian women's overall use of formal (mental health professional, medical provider) and informal (family/friends, printed material, internet, religious leader) mental health treatment use were analyzed with MANOVA. One-way post-hoc ANOVAs were used to examine differences in specific types of treatment sought (e.g., family/friend support). Differences between African American and Caucasian women's confidence in ratings of the helpfulness of treatment and their perceived barriers to treatment were analyzed with two sample $t$ tests. Paired $t$ tests were used to examine differences between all women's perceived concerns with barriers to treatment.

\section{Results}

\section{Participant information}

Four hundred forty-seven obstetrical patients initially completed the screening measures described. Rates of women recruited from the different clinic sites were closely equivalent; $41 \%$ ( $n=187)$ of the total sample were recruited from the suburban clinic, and $49 \%(n=260)$ were recruited from the urban clinics. Participant demographics by clinic are listed in Table 1. The suburban clinic sample comprised primarily white $(86 \%, n=160)$ and upper middle class (median family income $\$ 100,000)$ women. Women from the urban clinics were primarily African American (57\%, $n=148$ ) and living below national poverty levels $(87 \%, n=226)$. Rates of consent did not differ significantly between clinic sites, socioeconomic level and race.

African American women (chi-square $(1)=7.23, p<0.01$ ) were more likely than white women to complete the baseline interview. There were no other significant demographic differences between women who completed the interview and those who did not (included variables: age, weeks pregnant, marital status, years of school, work status, socioeconomic status, clinic site). African American women were significantly younger than white women (chi-square $(5)=$ 26.35, $p<0.001)$. Although most women were in a committed relationship (63\%, $n=64)$, African American women were more likely to be single (chi-square $(4)=20.68, p<$ 0.01 ) and to have more children than white women (chisquare $(1)=4.49, p<0.05)$. African American women in the sample had also obtained less education (chi-square $(7)=$ 
Table 2. Racial Differences in Mental Health Advice as Recently Sought by Women At Risk fOR DEPRESSION

\begin{tabular}{lccc}
\hline Source & $\begin{array}{c}\text { Endorsed } \\
\%(\mathrm{n})\end{array}$ & $\begin{array}{c}\text { African American } \\
\text { Mean }(S D)\end{array}$ & $\begin{array}{c}\text { White } \\
\text { Mean (SD) }\end{array}$ \\
\hline $\begin{array}{l}\text { Treatment use in previous } 6 \text { months } \\
\text { Family }\end{array}$ & $52(56)$ & $2.04(1.30)$ & $2.52(1.27)$ \\
Friends & $44(48)$ & $2.22(1.36)$ & $2.19(1.37)$ \\
Printed material & $40(43)$ & $1.84(1.02)$ & $1.64(.82)$ \\
Medical provider & $36(40)$ & $1.71(1.04)$ & $1.60(.94)$ \\
Internet & $14(15)$ & $1.24(.80)$ & $1.21(.57)$ \\
Religious leader & $10(11)$ & $1.38(1.01)$ & $1.60(.94)$ \\
Mental health professional & $12(13)$ & $1.33(.91)$ & $1.17(.62)$ \\
\hline
\end{tabular}

$36.39, p<0.01)$ and were more likely to be living in poverty than white women, (chi-square $(1)=48.86, p<0.001$ ).

Of the women screened overall, $39 \%(n=174)$ met criteria for risk for depression. The mean (M) EPDS score among the women who screened at risk (EPDS score $\geq 10$ or indication of past depression and current social stress) was 15.41 (SD 4.45).

\section{Treatment use history}

Only $12 \%$ ( $n=13$ of 108$)$ of the interviewed sample reported having any formal treatment by a medical provider or mental health professional in the 6 months prior to their baseline interview. (These results were replicated with a subsample of at-risk women limited to only those who had scored $\geq 10$ on the EPDS $(n=97)$. Only $12 \%(n=12)$ of those women had sought any kind of treatment.) However $52 \%$ ( $n=56$ of 108) of women indicated having used informal methods for support and information. Women's rank-ordered results, by race, regarding the frequency of mental health contact are shown in Table 2, indicating that women most frequently sought advice from family and friends and were least likely to turn to community/religious leaders, mental health professionals, and the internet. MANOVA results indicated there were no significant racial differences in rates of formal treatment use (mental health professional, medical provider), lambda $(2,106)=0.99$, NS. There were, however, significant differences in African American and white women's rates of informal treatment use, lambda (5, $103)=0.87, p=0.05$. Post-hoc ANOVAs demonstrated that African American women $(\mathrm{M}=1.38, \mathrm{SD}=0.11)$ were more likely to have spoken to a religious leader about mood than were white women $(\mathrm{M}=1.05, \mathrm{SD}=0.12), F(1)=4.20, p<$ 0.05 .

\section{Confidence in helpfulness of mental health treatment}

As women's willingness to seek treatment may be guided by their beliefs about what treatments are helpful, all women were asked about the extent to which they had confidence in provider, treatment, and delivery type. Women's reported confidence, including racial differences in their confidence for each subcategory, is shown in Table 3. Regarding provider type, women reported having the greatest levels of

Table 3. Racial Differences in Women's Reported Confidence in Treatment

\begin{tabular}{|c|c|c|c|c|c|c|c|c|}
\hline Source & $\begin{array}{c}\text { Endorsed } \\
\%\end{array}$ & $\begin{array}{c}\text { African } \\
\text { American } \\
\text { Mean (SD) }\end{array}$ & $\begin{array}{c}\text { White } \\
\text { Mean (SD) }\end{array}$ & $\mathrm{t}$ & df & Significance & $\begin{array}{r}95 \\
\text { Conf } \\
\text { inte }\end{array}$ & $\begin{array}{l}5 \% \\
\text { idence } \\
\text { erval }\end{array}$ \\
\hline \multicolumn{9}{|l|}{ Confidence in provider } \\
\hline Mental health specialist & 85.1 & $3.31(1.43)$ & $3.47(1.18)$ & -0.81 & 107 & 0.42 & -0.69 & 0.37 \\
\hline Pastor & 60.5 & $3.45(1.23)$ & $2.79(1.27)$ & 2.34 & 107 & 0.02 & 0.03 & 3.60 \\
\hline Primary care physician & 68.8 & $2.86(1.26)$ & $2.90(1.10)$ & -0.32 & 107 & 0.75 & -0.18 & 0.13 \\
\hline Obstetrician/gynecologist & 62.5 & $2.61(1.34)$ & $2.69(1.15)$ & -0.46 & 107 & 0.64 & -0.20 & 0.13 \\
\hline Community liaison & 29.2 & $2.04(1.24)$ & $2.00(0.92)$ & -0.16 & 107 & 0.88 & -0.17 & 0.14 \\
\hline Child's pediatrician & 33.3 & $1.80(1.21)$ & $1.89(1.07)$ & -0.56 & 107 & 0.58 & -0.21 & 0.12 \\
\hline \multicolumn{9}{|c|}{ Confidence in treatment helping } \\
\hline Therapy & 76.4 & $3.18(1.41)$ & $3.19(1.32)$ & -1.1 & 107 & 0.27 & -0.21 & 0.060 \\
\hline Family/friend support & 89.6 & $3.12(1.2)$ & $3.52(1.03)$ & -1.75 & 107 & 0.08 & -0.27 & 0.02 \\
\hline Antidepressant & 68.7 & $2.42(1.3)$ & $3.04(1.2)$ & -2.57 & 107 & 0.01 & -0.38 & -0.05 \\
\hline Case management & 62.5 & $2.35(1.38)$ & $2.60(1.16)$ & -1.18 & 107 & 0.24 & -0.27 & 0.07 \\
\hline \multicolumn{9}{|c|}{ Confidence in treatment delivery locale } \\
\hline Professional office & 91.7 & $3.24(1.33)$ & $3.96(1.03)$ & -2.91 & 107 & 0.01 & -0.37 & -0.07 \\
\hline Home & 68.8 & $3.47(1.39)$ & $3.25(1.43)$ & 0.72 & 107 & 0.48 & -0.11 & 0.24 \\
\hline Religious setting & 60.4 & $3.45(1.21)$ & $2.85(1.35)$ & 2.28 & 107 & 0.03 & 0.02 & 0.35 \\
\hline Telephone & 45.8 & $2.10(1.16)$ & $2.56(1.46)$ & -1.60 & 107 & 0.16 & -0.31 & 0.03 \\
\hline Community setting & 35.4 & $2.00(1.19)$ & $2.13(1.35)$ & 0.40 & 107 & 0.70 & -0.21 & 0.14 \\
\hline Internet & 27.1 & 1.47 (0.92) & $1.96(1.30)$ & -2.16 & 107 & 0.03 & -0.32 & -0.13 \\
\hline
\end{tabular}


confidence in treatment received from a mental health specialist or pastor, followed by medical professionals (e.g., primary care physician, obstetricians/gynecologists). African American women expressed significantly greater confidence in treatment delivered by a pastor than did white women. Women also expressed high levels of confidence in treatments that were psychosocially based. Specifically, therapy and support from family received the highest rankings of confidence. Case management and antidepressants were ranked lowest in terms of expressed confidence. African American women were significantly less likely to report confidence in family or friend support and in antidepressants helping them with their mood symptoms than were white women. Lastly, women reported high levels of confidence in treatments delivered in professional and home settings and expressed low levels of confidence in the helpfulness of treatments delivered in community settings (e.g., a neighborhood center, library) or via the internet. However, African American women expressed less confidence in treatments delivered in a professional setting than did white women. African American women also had particularly low ratings of confidence in treatments delivered via the internet in comparison to white women. In contrast, African American women expressed more confidence in treatments delivered in a religious setting than did white women.

\section{Treatment barriers}

Women's reported concerns with barriers to mental health treatment use were examined. Women reported more concern with structural barriers $(\mathrm{M}=10.56, \mathrm{SD}=5.56)$ as compared with knowledge $(\mathrm{M}=7.43, \mathrm{SD}=3.32, t(107)=5.31$, $p=0.003)$ and attitudinal $(\mathrm{M}=6.95, \mathrm{SD}=4.62)$ barriers $(t(107)=6.61, p=0.000)$. There were no significant overall differences in women's expressed concerns with knowledge and attitudinal barriers. Women's mean rankings of structural barriers of greatest concern were as follows: insurance $(\mathrm{M}=2.56, \mathrm{SD}=1.78)$, inability to pay $(\mathrm{M}=2.23, \mathrm{SD}=1.52)$, transportation $(\mathrm{M}=2.16, \mathrm{SD}=1.50)$, and inadequate child care $(\mathrm{M}=2.07, \mathrm{SD}=1.35)$. Within knowledge barriers, women were least sure whom to contact $(\mathrm{M}=2.16, \mathrm{SD}=$ 3.25) and did not know the best treatment for their depression $(\mathrm{M}=2.06, \mathrm{SD}=1.26)$. Finally, women's greatest attitudinal barriers were their lack of expressed motivation for treatment $(\mathrm{M}=2.06, \mathrm{SD}=1.17)$ and hopelessness about treatment working $(\mathrm{M}=1.80, \mathrm{SD}=1.16)$. There were no significant differences in the extent to which African American and white women endorsed difficulties with structural, knowledge, or attitudinal barriers.

\section{Discussion}

The primary aim of this study was to examine women's beliefs and barriers to depression treatment during the perinatal period. In addition, given differential rates of depression treatment use between African American and white women, this study sought to explore racial differences in women's beliefs and barriers to treatment.

The current study found high rates of elevated EPDS scores and histories of past depression. The majority of women who had experienced previous depressive symptoms also endorsed current elevated depressive symptomatology. Consistent with previous research, few women in- terviewed had sought any kind of formal treatment. ${ }^{5}$ Those who did seek treatment were most likely to have spoken to their medical provider and least likely to have spoken with a mental health provider. Other research in this area has found that previous contact with a mental health professional predicts recent use of treatment from a mental health professional, suggesting that women turn to treatment from individuals with whom they are most familiar. ${ }^{20}$

In contrast to previous research that found lower rates of mental health treatment use among African American individuals, ${ }^{6,7}$ there were no significant differences in formal mental health treatment use between African American and white women in this study. This discrepancy may be due to the availability of mental healthcare clinicians in the clinics from which the women were recruited. The urban clinics, where many of the African American women were recruited, routinely screened for depression in pregnant women. Those women who met clinic criteria for depression risk were then asked to speak with an on-site social worker, who discussed their mood with them and provided them with treatment referrals. Thus, the results regarding formal mental health treatment use in African American women may not be generalizable to clinics without exposure to these resources. It is notable that despite implementation of screening and regular follow-up with African American women, overall rates of treatment use remained low, suggesting that additional treatment engagement efforts may be warranted.

Women, regardless of race, reported that they were most likely to have used informal treatment, such as seeking advice and support from friends and family or from printed material. These findings are consistent with research suggesting that distressed individuals often turn first to informal forms of treatment. ${ }^{41,42}$ Psychoeducational or brief therapeutic strategies that improve family and friend support among mildly symptomatic women may be highly acceptable to women. Notably, African American and white women used different types of informal treatment. Consistent with emerging literature on the importance of religion in the African American community, ${ }^{43}$ African American women were more likely than white women to have spoken to a religious leader about their mood.

Women reported they had greatest confidence in psychotherapy and support received from family and friends and least confidence in antidepressant medication and case management as forms of treatment. African American women expressed significantly more doubt about antidepressant medication than did white women. Recent studies that provided psychoeducation about antidepressants and their efficacy in nonpregnant or breastfeeding depressed populations have found that these brief interventions have improved willingness to take antidepressants. ${ }^{44}$ Given emerging conflicting data on the safety of antidepressants during pregnancy ${ }^{9,10}$ and the existence of efficacious psychotherapies, however, it is also important to improve pregnant women's awareness of and access to psychotherapy as a treatment option. Efforts at improving psychoeducation about antidepressants and the availability of therapy may be particularly important for African American women.

Women in this study expressed greatest confidence in mental health specialists, the provider type with whom they were least likely to have had any form of contact. Given that access and familiarity are linked to provider use, improving 
access to mental health providers, such as having on-site mental health clinicians, may improve women's use of mental health professionals. Religious leaders also received high levels of confidence, particularly among African American women. Such results suggest that training religious leaders in depression-specific psychotherapies may be an especially effective way of reaching a broader range of women in need of treatment.

The perinatal period may present unique difficulties to accessing treatments in traditional locales (e.g., a professional office). A number of depression treatment outcome studies have attempted to remedy access problems by delivering treatment in the home, ${ }^{45}$ over the internet, ${ }^{46}$ in supermarkets, ${ }^{47}$ or via telephone. ${ }^{48}$ It is less clear how women perceive these different forms of treatment delivery. In the present study, women indicated that they had greatest confidence in treatments delivered in a professional office, followed by treatments delivered at home. They reported intermediate levels of confidence in treatments delivered over the telephone and in religious settings, although African American women expressed greater confidence than did white women in treatment delivered in a religious setting. Community settings and the internet were endorsed with the least amount of confidence. African American women expressed particularly low levels of confidence in treatment delivered via the internet.

Although women's beliefs about treatment may serve as prompts to seek out treatment, it is also important to know what factors act as barriers to treatment use. In this study, women were significantly more concerned with structural barriers than with either knowledge or attitudinal barriers. There were no significant differences in African American and white women's perceived barriers, suggesting that both groups of women are concerned about similar difficulties in accessing treatment. These results point to important areas of concern for women that may be addressed through both system and individual level changes. For instance, improved education (e.g., making women aware of treatment payment options) and changes in treatment delivery to offset structural barriers (e.g., providing treatment via telephone in order to overcome transportation and child care concerns) may help to address women's barriers and improve their willingness to use treatment.

\section{Limitations}

Corroborating data about the specific forms and intensity of formal treatment were not gathered in this study. Related research in this area has found that treatment is often marked by low dose (e.g., low medication dose $\mathrm{e}^{49}$ ), low number of attended therapy sessions, ${ }^{50}$ and poor adherence, ${ }^{51}$ suggesting that some of the women in this study may have received suboptimal treatment. Future studies that gather medical record and pharmacy information, in addition to participant responses about number of sessions attended, medications prescribed, and prescriptions filled, may provide better distinctions between simple treatment use and the receipt of efficacious treatment.

The lack of available longitudinal data in this study limits conclusions about the impact of women's beliefs and perceived barriers on their treatment use over time and, ultimately, on their depression outcomes. However, previous research has demonstrated that beliefs about treatment and perceived barriers are important determinants of both willingness to seek treatment and delays in actually engaging in treatment. ${ }^{14,26}$ It is possible that women's confidence in treatment type may vary between those who sought treatment and those who did not. The low number of participants in this study precluded such examinations, however. Future research with larger samples is needed to examine factors impacting women's beliefs about treatment, including possible differences across broader racial groups.

It is possible that some of the perceived barriers assessed in this study may be unique to the perinatal period or, more specifically, pregnancy. Longitudinal and cross-sectional research examining differences in perceived barriers to treatment in women during the perinatal period and other periods of life are needed, in addition to comparisons between pregnant and nonpregnant women.

Differences in administering the interview over the telephone or in person may have introduced a bias in women's responses. Previous research, however, has found no significant differences in the validity of psychiatric interviews delivered via telephone or in person. ${ }^{52,53}$

Finally, although this study consisted of a relatively balanced racial and socioeconomic sample, the rate of attrition was somewhat high. Notably, African American women were more likely to complete the interview than were white women. Such rates of attrition are consistent with previous research with lower-income, community, and clinic samples $^{39,40}$ and reflect difficulties in conducting research with multiply stressed individuals.

This study provides initial data suggesting that women have identifiable beliefs about treatment, and these beliefs vary in important ways across African American and white women. Given low rates of treatment use among depressed women, it is important to improve education about treatment options as well as the effectiveness of available treatments. Understanding women's beliefs about treatment and their perceived barriers to treatment provides a basis for customizing treatment based on their expectancies and needs and, ultimately, improving treatment use. Additional research investigating women's beliefs may help to guide the ways in which treatment referrals and delivery are conducted to better meet women's needs and the use of mental health treatment.

\section{Disclosure Statement}

No competing financial interests exist.

\section{References}

1. Gaynes BN, Gavin N, Meltzer-Brody S, et al. Perinatal depression: Prevalence, screening accuracy, and screening outcomes. Evid Rep Technol Assess (Summ) 2005;119:1-8.

2. Breslau J, Kendler K, Maxwell S, et al. Lifetime risk and persistence of psychiatric disorders across ethnic groups in the United States. Psychol Med 2005;35:317-320.

3. Sotsky SM, Glass DR, Shea MT, et al. Patient predictors of response to psychotherapy and pharmacotherapy: Findings in the NIMH Treatment of Depression Collaborative Research Program. Am J Psychiatry 1991;148:997-1008.

4. Weinberger J, Eig A. Expectancies: The ignored common factor in psychotherapy. In: Kirsch I, ed. How expectancies 
shape experience. Washington, DC: American Psychological Association, 1999:357-382.

5. Flynn HA, O'Mahen HA, Massey L, Marcus S. The impact of a brief obstetrics clinic-based intervention on treatment use for perinatal depression. I Womens Health 2006;15:11951204.

6. Carrington $\mathrm{CH}$. Clinical depression in African American women: Diagnoses, treatment, and research. I Clin Psychol 2006;62:779-791.

7. Das AK, Ofson M, McCurtis HL, Weissman MM. Depression in African Americans: Breaking barriers to detection and treatment. I Fam Pract 2006;55:30-39.

8. Weissman MM, Pilowsky DJ, Wickramaratne PJ, et al. Remissions in maternal depression and child psychopathology: A STAR*D-child report. IAMA 2006;295:1389-1398.

9. Ferreira E, Carceller AM, Agogue C, et al. Effects of selective serotonin reuptake inhibitors and venlafaxine during pregnancy in term and preterm neonates. Pediatrics 2007;119:52-59.

10. Djulus J, Koren G, Einarson TR, et al. Exposure to mirtazapine during pregnancy: A prospective, comparative study of birth outcomes. J Clin Psychiatry 2006;67:1280-1284.

11. Oberlander TF, Warburton W, Misri S, et al. Neonatal outcomes after prenatal exposure to selective serotonin reuptake inhibitor antidepressants and maternal depression using population-based linked health data. Arch Gen Psychiatry 2006;63:898-906.

12. Scholle SH, Haskett RF, Hanusa BH, et al. Addressing depression in obstetrics/gynecology practice. Gen Hosp Psychiatry 2003;25:83-90.

13. Simon GE, Ludman EJ, Tutty S, et al. Telephone psychotherapy and telephone care management for primary care patients starting antidepressant treatment: A randomized controlled trial. JAMA 2004;292:935-942.

14. Thompson A, Hunt C, Issakidis C. Why wait? Reasons for delay and prompts to seek help for mental health problems in an Australian clinical sample. Soc Psychiatry Psychiatr Epidemiol 2004;39:810-817.

15. Meyer B, Pilkonis PA, Krupnick JL, et al. Treatment expectancies, patient alliance, and outcome: Further analyses from the National Institute of Mental Health Treatment of Depression Collaborative Research Program. J Consult Clin Psychol 2002;70:1051-1055.

16. Leaf PJ, Weissman MM, Holzer CE, et al. Contact with health professionals for the treatment of psychiatric and emotional problems. Med Care 1985;23:1322-1337.

17. Mojtabai R, Olfson M, Mechanic D. Perceived need and helpseeking in adults with mood, anxiety, or substance abuse disorders. Arch Gen Psychiatry 2002;59:77-84.

18. Bayer JK, Peay MY. Predicting intentions to seek help from professional mental health services. Aust NZ J Psychiatry 1997;31:504-513.

19. Jorm AF, Christensen H, Medway J, et al. Public belief systems about the helpfulness of interventions for depression: Associations with history of depression and professional help-seeking. Soc Psychiatry Psychiatr Epidemiol 2000;35: 211-219.

20. Alvidrez J, Azocar F. Distressed women's clinic patients: Preferences for mental health treatments and perceived obstacles. Gen Hosp Psychiatry 1999;21:340-347.

21. Scholle SH, Kelleher K. Preferences for depression advice among low-income women. Matern Child Health J 2003;7: 95-102.

22. Wang J, Patten SB, Williams JV, et al. Help-seeking behaviours of individuals with mood disorders. Can J Psychiatry 2005;50:652-659.
23. Amankwaa LC. Postpartum depression among AfricanAmerican women. Issues Ment Health Nurs 2003;24:297316.

24. Cooper LA, Gonzales JJ, Gallo JJ, et al. The acceptability of treatment for depression among African-American, Hispanic, and white primary care patients. Med Care 2003;41: 479-489.

25. Newport DJ, Calamaras MR, Devane CL, et al. Atypical antipsychotic administration during late pregnancy: Placental passage and obstetrical outcomes. Am J Psychiatry 2007;164: 1214-1220.

26. Wang PS, Gilman SE, Guardino M, et al. Initiation of and adherence to treatment for mental disorders: Examination of patient advocate group members in 11 countries. Med Care 2000;38:926-936.

27. Sareen J, Jagdeo A, Cox BJ, et al. Perceived barriers to mental health service utilization in the United States, Ontario, and the Netherlands. Psychiatr Serv 2007;58:357-364.

28. Ojeda VD, McGuire TG. Gender and racial/ethnic differences in use of outpatient mental health and substance use services by depressed adults. Psychiatr Q 2006;77:211-222.

29. Schraufnagel TJ, Wagner AW, Miranda J, Roy-Byrne PP. Treating minority patients with depression and anxiety: What does the evidence tell us? Gen Hosp Psychiatry 2006;28:27-36.

30. Boath E, Bradley E, Henshaw C. Women's views of antidepressants in the treatment of postnatal depression. I Psychosom Obstet Gynaecol 2004;25:221-233.

31. Hickey AR, Boyce PM, Ellwood D, Morris-Yates AD. Early discharge and risk for postnatal depression. Med J Aust 1997;167:244-247.

32. Carter FA, Carter JD, Luty SE, et al. Screening and treatment for depression during pregnancy: A cautionary note. Aust NZ J Psychiatry 2005;39:255-261.

33. Cox JL, Holden JM, Sagovsky R. Detection of postnatal depression. Development of the 10-item Edinburgh Postnatal Depression Scale. Br J Psychiatry 1987;150:782-786.

34. Hankin BL, Abramson LY. Development of gender differences in depression: An elaborated cognitive vulnerabilitytransactional stress theory. Psychol Bull 2001;127:773-796.

35. Leskela U, Rytsala H, Komulainen E, et al. The influence of adversity and perceived social support on the outcome of major depressive disorder in subjects with different levels of depressive symptoms. Psychol Med 2006;36:779-788.

36. Adouard F, Glangeaud-Freudenthal NM, Golse B. Validation of the Edinburgh Postnatal Depression Scale (EPDS) in a sample of women with high-risk pregnancies in France. Arch Womens Ment Health 2005;8:89-95.

37. Horowitz JA, Goodman J. A longitudinal study of maternal postpartum depression symptoms. Res Theory Nurs Pract 2004;18:149-163.

38. McCoy SJ, Beal JM, Shipman SB, et al. Risk factors for postpartum depression: A retrospective investigation at 4-weeks postnatal and a review of the literature. J Am Osteopath Assoc 2006;106:193-198.

39. Hobfoll SE, Ritter C, Lavin J, et al. Depression prevalence and incidence among inner-city pregnant and postpartum women. J Consult Clin Psychol 1995;63:445-453.

40. Miranda J, Green BL, Krupnick JL, et al. One-year outcomes of a randomized clinical trial treating depression in low-income minority women. I Consult Clin Psychol 2006;74:99111.

41. Jorm AF, Christensen H, Griffiths KM. The impact of beyondblue: The national depression initiative on the Australian public's recognition of depression and beliefs about treatments. Aust NZ J Psychiatry 2006;40:42-46. 
42. Jorm AF, Mackinnon A, Christensen H, Griffiths KM. Structure of beliefs about the helpfulness of interventions for depression and schizophrenia. Results from a national survey of the Australian public. Soc Psychiatry Psychiatr Epidemiol 2005;40:877-883.

43. Musgrave CF, Allen CE, Allen GJ. Spirituality and health for women of color. Am J Public Health 2002;92:557-560.

44. Bonari L, Koren G, Einarson TR, et al. Use of antidepressants by pregnant women: Evaluation of perception of risk, efficacy of evidence based counseling and determinants of decision making. Arch Womens Ment Health 2005;8:214220.

45. Chabrol H, Teissedre F, Saint-Jean M, et al. Prevention and treatment of post-partum depression: A controlled randomized study on women at risk. Psychol Med 2002;32:10391047.

46. Griffiths KM, Christensen H, Jorm AF, et al. Effect of webbased depression literacy and cognitive-behavioural therapy interventions on stigmatising attitudes to depression: Randomised controlled trial. Br J Psychiatry 2004;185:342-349.

47. Swartz HA, Shear MK, Frank E, et al. A pilot study of community mental health care for depression in a supermarket setting. Psychiatr Serv 2002;53:1132-1137.

48. Mohr DC, Hart SL, Julian L, et al. Telephone-administered psychotherapy for depression. Arch Gen Psychiatry 2005;62:1007-1014.
49. Melfi CA, Croghan TW, Hanna MP. Access to treatment for depression in a Medicaid population. J Health Care Poor Underserved 1999;10:201-215.

50. Croghan TW, Lair TJ, Engelhart L, et al. Effect of antidepressant therapy on health care utilization and costs in primary care. Psychiatr Serv 1997;48:1420-1426.

51. Vergouwen AC, Bakker A, Katon WJ, et al. Improving adherence to antidepressants: A systematic review of interventions. J Clin Psychiatry 2003;64:1415-1420.

52. Wells KB, Stewart A, Hays RD, et al. The functioning and well-being of depressed patients. Results from the Medical Outcomes Study. JAMA 1989;262:914-919.

53. Hermens ML, Ader HJ, van Hout HP, et al. Administering the MADRS by telephone or face-to-face: A validity study. Ann Gen Psychiatry 2006;22:3.

Address reprint requests to: Heather O'Mahen, Ph.D. Washington Singer Building School of Psychiatry University of Exeter Exeter U.K. Ex4 4QG

E-mail: h.o'mahen@ex.ac.uk

\section{Appendix: Barriers Scale}

"To what extent do the following factors prevent you from seeking treatment?"

\section{Structural barriers}

1. Insurance does not cover

2. Inability to pay

3. Inadequate child care

4. Transportation

5. Distance to travel to clinic

\section{Knowledge barriers}

1. Do not have time

2. Not sure who to contact

3. Not sure how to set up an appointment

4. Do not know what treatment might be best for me

\section{Attitudinal barriers}

1. Worried about what others will think

2. Do not think I can be helped effectively

3. My family does not support my getting treatment

4. It is difficult to become motivated to seek treatment 
This article has been cited by:

1. Kathy Crockett, Caron Zlotnick, Melvin Davis, Nanetta Payne, Rosie Washington. 2009. A depression preventive intervention for rural low-income African-American pregnant women at risk for postpartum depression. Archives of Women's Mental Health 11:5-6, 319-325. [CrossRef] 